\title{
Structuring the Imagination
}

Author: Coeli M. Small

Faculty Mentor: Jeanne Tunks, Department of Teacher Education and Administration, College of Education

College and Affiliation: Department of Teacher Education and Administration, College of Education 


\section{Bio:}

Coeli Small graduated in May 2013 from the University of North Texas with a Bachelor of Interdisciplinary Studies degree that focused on elementary education. She also received a secondary certification in teaching English as a second language. She is currently pursuing a career that cultivates her creativity both locally and globally. This research is a starting point for Coeli as she searches for more opportunities in which she can demonstrate to children around the world how to engage their imagination through reading and writing. She is currently based in Texas and one day dreams of being an author. 


\begin{abstract}
:
This action research focused on igniting third grade students' imagination during creative writing activities. Following observations of the lack of imagination in creative writing by elementary schools, this study was conducted in a third grade classroom based on the hypothesis that explicit instruction on sensory imagery, synonyms and antonyms, and onomatopoeia would influence an increase in imaginative writing. Researchers of creative writing state that explicit instruction of the imagination in creative writing will increase students' use of their imaginations without being prompted. This theoretical position was tested in this action research. Pre-instructional writing samples showed limited imagination in students' writing. Post-instructional writing samples showed little or no change in student writing, although changes in weekly writing skills showed gains in some of the writing conventions presented. The imaginative and explicit instruction of the content did not transfer to the students' non-prompted writing. Various factors contributed to these findings.
\end{abstract}




\section{Introduction}

Albert Einstein stated, "Imagination is more important than knowledge." Could it be possible that the father of knowledge believed in a power greater than knowledge itself that pushes our world forward? If this is indeed true, then the American public school system should reconsider its current drive for increased knowledge and the assessment of it through extensive accountability measures. Schools are highly driven by state standards and examination scores for multiple reasons, including increased funding as a result of higher scores. Education is currently a puzzle in which teachers must find a balance between instructing the child directly for the test and instructing the child on what is important by engaging the imagination; the latter of which could potentially empower and accelerate the child toward inventiveness and greatness. One of the few outlets for imagination, recess, is being curbed to thirty minutes during an eight-hour day of sitting in desks, which results in insufficient imaginative time. The imagination seen on the playground is not being seen in the classroom (Mills, 1983). Something is becoming lost in translation. Albert Einstein went on to say, “...knowledge is limited to all we know and understand, while imagination embraces the entire world, and all there ever will be to know and understand," (p. 50). Albert Einstein had the key to the future, and currently, teachers are trapped by the wave of accountability and fear, choosing to ignore the opportunity to ignite imagination in children.

\section{Background}

What is imagination? How should it be defined? Susan Barber (2003) defines imagination as "the mind in flight, soaring on the wings of memory, emotion, association and perception" p. 2). Imagination is what frees us, but relies heavily on our own perceptions and experiences. Lisa Dart (2001) interviewed English department heads about how they defined 
imagination (p. 67). One educator said she feels that imagination is the emotional engagement we have with the world, while another educator said that imagination is taking the time to empathize with others in order to understand what being human means. While I agree with both of these statements, the definition that aligns closest with my own was given by the third educator; that "In terms of creativity, it's got to be the capacity to be original, able to invent, to project, able to identify, able to anticipate, able to transfer situations and put oneself in the place of the other," (p. 67). If imagination is a mixture of creating, inventing, and projecting, creative writing is the most accurate avenue in which academic student imagination will be shown. Beth Mills (1983) states, "Language arts, if taken to mean primarily writing, is a subject in which we especially want to encourage children's imaginations" (p. 51).

Susan Barber (2003) says, "Imagination is crucial to good writing, and at the same time, undeniably connected to the acquired skills and knowledge," (p. 2). Imagination tends to be considered a freeing exercise - absent of structure and instruction. She goes on to say, "Spontaneous, imaginative play does not come naturally to children but is to a large extent influenced by their immediate surroundings and the adults close to them" (p. 51). Therefore, it is the job of the educator to influence imagination use academically, because students will not naturally use their imaginations while writing. Maxwell Littwin (1935) agrees that imagination takes training (p. 660). What is true is that if imagination is to be used academically, in the form of creative writing, it must be taught within contexts, with constant modeling, and with explicit instruction on creative writing skills. Creative writing is not just thinking on paper. It consists of multiple elements that can be taught in various ways to all students (Cook, 1931). What was true then is true now_children can be taught to be imaginative, particularly in writing. 
According to Gail Tompkin (2012), word choice, sensory imagery, and figurative language are the skills that make up imaginative and creative writing. Lisa Pavlik (2011) states that "imagination is structured in certain ways, and that these structures lead to creativity during story writing" (Pavlik, 2011, p.132). One cannot separate the imaginative from the academic. When someone reads a piece of imaginative text, the author's word choice, use of sensory imagery, and language use are responsible for drawing the reader into the writing. This interest then leads the reader to activate his imagination. The ability of the reader to use imagination while reading will depend on how the author activates the reader's personal imagination through the use of writing conventions. Lisa Dart (2001) asked the English department heads what they thought imagination looked like academically. They responded that they believe imagination is the amount of student engagement, originality, creativity, and the use of words that give the reader a mental image. Instruction should revolve around igniting these actions and feelings in the students. When delivering instruction on how to activate the imagination academically, instructors must teach the content within context through a genuine experience (Barber, 2003). It is the educator's responsibility to model the use of the imagination through the use of creative writing that is both important and meaningful to the students.

\section{Hypothesis}

It was hypothesized that explicit instruction that engages creative writing skills and activates students' imaginations would result in an increase in imaginative, creative, unprompted writing among third grade students.

\section{Action Research Format}

This action research was conducted as a requirement for interns, who worked as student teachers, for the Professional Development School program for educators at the University of 
North Texas. Action Research is the process of conducting research in an authentic setting where a discrepant phenomenon occurs, warranting further investigation in the form of research, which leads to an action for changing practice to overcome the discrepancy. In the third-grade classroom where this study was conducted, the discrepancy observed was the lack of use of imagination among third graders when writing. The study was proposed to overcome this discrepancy by introducing structured language arts lessons that supported increased use of imagination when writing. In the program where this action research was conducted there are three options for completing the work. First, the intern and the mentor teacher can work together to create the study and conduct the research; second, the mentor teacher can tell the intern what to research and have them conduct the research; or third, the intern can come up with the research question and conduct the research himself. The third method was employed for this study.

\section{Setting and Population}

The study was carried out in an affluent elementary school where $76 \%$ of students are were white, 3\% are African American, 14\% are Hispanic, and 7\% are of other ethnicities. Various other economic and linguistic factors defined the population: $8 \%$ of the students are economically disadvantaged, 4\% are Limited English Proficient (LEP) students, and 10\% of the students were at-risk. The suburban school is heavily supported, both financially through a foundation, and through parent involvement in the forms of a strong Parent Teacher Association, and parent volunteerism in the school. The affluent students enjoy considerable support from parents, who expect them to perform at a high level academically. The school's State of Texas exemplary rating suggests that this expectation is met.

\section{Procedure}


This action research was conducted over a six-week period. The first week and sixth week were used for pre- and post- assessments. Weeks two through five consisted of creative writing lessons that were presented each Wednesday and Thursday. Lessons lasted 20 minutes each, and students had 20 minutes of writing and skill building practice afterwards. On Fridays, students had a 40 minute block of time to complete any of the writing that they did not finish on Wednesday or Thursday. All work samples from each week were collected on Friday afternoons.

\section{Week 1}

During the first week, a pre-assessment was administered to determine if students were using their imaginations when given a creative writing prompt, and if they were, then how so. The prompt was the picture titled Another Time, Another Place, by Chris Van Allsburg (1984).

The students were shown the piece of illustrative art and instructed to write a story to go along with the picture. No other instructions were given. Many students asked questions such as, “What do you mean?”, "How long does it need to be?”, and "How do I write a story to this picture?" The students were continually encouraged to write a story to go with the picture. Many students took over ten minutes to inspect the art in search of clarification before finally beginning to write. Each writing sample was reviewed using a rubric.

\section{Week 2}

Based on the results of the pre-writing opportunity a four-week, structured protocol, for introducing the elements of creative writing was developed. In the first weeks of intervention, the topic of sensory imagery was introduced by reading the book The Story of Frog Belly Rat Bone by Timothy Basil Ering (2008). This book served as a mentor text because it modeled good use of sensory imagery by its use of descriptive words, sensory imagery that related to the illustrations, an abundance of examples of characterization, and expressive writing. 
The students closed their eyes and listened to the story once for comprehension. They saw no pictures. After the first reading, the students were told that they would be drawing a picture of something they visualized during the story. They closed their eyes again and listened a second time. Afterwards, options were listed for the students to draw. They were encouraged to draw a picture of the treasure, the garden, Cementland, and/or Frog Belly Rat Bone. These four parts of the story were selected because their descriptions were based solely on the author's use of sensory imagery and placed a visual image in the minds of the readers.

On day two of this week, specific students shared their pictures. They described clues, or word choice, in the story they heard that prompted them to draw their picture a certain way. For example, one student said that he drew bony arms for Frog Belly Rat Bone because the book specifically stated that Frog Belly Rat Bone had long, bony arms and legs. As the students described their use of sensory language that was part of the drawings, a sensory imagery tree map was created that listed each of the five senses. As students explained their reasoning and word proof from the story that prompted their drawing, these answers were listed under the appropriate sense on the chart. The intern and students discussed that good writers use sensory imagery to create pictures in their readers' minds. It was explained that the five senses are used to create mental pictures, because they cause the reader to draw upon specific experiences to relate or build a picture.

The students took turns looking around the room and describing objects using sensory imagery. As they came up with the words, they would add them to the appropriate section of the sense chart. Finally, students worked together to write a paragraph describing summer break experiences using sensory language, following a model by the intern. The students were then asking to create their own paragraphs, using sensory imagery, describing a season that had 
meaning for them. To help the students get started they were given examples such as the following: "in the summertime, it is humid and dry. Your feet will burn on the hot ground if you do not wear shoes." Students worked independently. Student work samples were collected.

\section{Week 3}

Week two of the intervention phase of the study focused on synonyms, antonyms, and word choice. The intern came into the classroom wearing an apron and holding a mixing bowl and a whisk. The students were told that the intern had been cooking up writing all weekend, but many of the ingredients were expired. A paragraph of writing was extracted from the bowl and displayed for the students on the document camera. The expired words were words that were general and "tired," such as love, went, and good. These types of words were highlighted in red ink. Students were instructed to switch the expired words and replace them with synonyms. Plastic Easter eggs were placed around the room. Each egg had a number from 1 through 11 and a tired word written on the outside. On the inside, three synonyms for the word and one antonym were written. For example, the first egg had the number 1 on the outside, as well as the word LOVE. The inside of the egg contained a piece of paper with the synonyms "adore," "enjoy," and "cherish." This egg also included the antonym "hate." Students received a copy of the paragraph and were sent in pairs to crack the eggs open and choose a synonym that would best replace the tired words in the story. Students were up, moving, and working together to re-write the story. Once the work was completed, each group shared the way that they changed the original story's tired words. The class discussed how the writing had become better after they replaced the tired words. The class also discussed the importance of synonyms and antonyms in engaging a reader and creating better writers. 
On day two, synonyms and antonyms were reviewed and modeled instruction was provided on how to find these in a thesaurus. A poem was read, in which all of the synonyms had changed into tired words. A second reading of the poem, with the synonyms, showed students how the poem changed to be more enjoyable to the reader. Each student received a tired word. They looked the word up in a thesaurus and chose three synonyms to replace it, then created a three-line poem using the tired word and its synonyms. Work samples were collected.

\section{Week 4}

During the third week of the intervention, the class used a lesson from a unit on onomatopoeia that the district had published. Students examined comic books and noted when words were used to represent sounds that the characters used to express actions emotions, and excitement. Students then created their own comic. This writing lesson was taught in conjunction with a science unit on force and motion. Students had been studying force and motion for one week, and were familiar with the vocabulary and content. This cross-curricular assignment was a test of how well the students comprehended the science material as well as the convention of onomatopoeia. Students were given thirty minutes each day for five days to complete their comic. This was the most time allotted to any of the writing conventions, as well as the only convention to be taught in addition to another curricular area. Students illustrated their comic, wrote a cohesive story from their imaginations, added their background knowledge on comics, and created a superpower of the hero based on force and motion. Work samples were collected.

\section{Week 5}

In the fourth and final week of the intervention part of the action research students applied the three conventions (imagery, synonyms, and onomatopoeia) in an imaginary writing context. The intent was to provide practice in using all three prior to the post-assessment during 
week six. The intern and students created an outline of an imaginative story containing: who, what, when, where, why, and how, main characters, setting, and problem. Sitting on the floor in a circle, the intern and students verbally created an imaginary story. The method used to create the story involved using the three conventions, which were directed by the intern leading the group, and a ball of yarn, that when held, resulted in a completed sentence that added depth to the story. After a sentence was formed, the author of the sentence held the string and tossed the ball of yarn to a different student. This continued until all three conventions were used multiple times. The class created a "story web" from the yarn, showing students in a tactile and visual way how to create stories.

On the second day, the following acrostic poem was introduced:

Free writes for practice

Adds onomatopoeia

Neatly shares their work

Tells a story with who, what, when, where, why, and how

Attaches antonyms

Slips in synonyms

Thinks with their imagination

Includes sensory imagery

Can use you a thesaurus

The first bolded letter of each sentence spelled the word FANTASTIC. The intern created the acrostic poem this way in order to remind students of the conventions they had learned, as well as the skills that writers use in order to create fantastic writing. Students wrote an imaginative story that used each of the conventions listed. This writing opportunity provided 
more practice with explicit instruction prior to writing an unprompted piece the following week. Writing samples were collected.

In addition, students received all of their completed writing samples from previous weeks, which included written, corrective feedback. Students had time to ask for clarification with the intent to improve. At this point in this action research, all explicit instruction ceased.

\section{Week 6}

The final week was used for the post-assessment. The intern re-posted the picture that was used in week one. Students received the same directions - to write a story based on the picture. Work samples were collected.

\section{Data Analysis and Results}

The pre-assessment and post-assessment writings that described the painting were assessed using the rubrics in Table 1. Each paper was read and the rubric applied to it, resulting in scores ranging from 3 to12. Tables 1 and 2 show the rubric and scores on the pre-assessment. During the first week the pre-assessment results were analyzed with the rubric from Table 1.

Students received a 1, 2, or 3 (1 being the lowest and 3 being the highest) on each element based on how often they used it in the writing. Only one student received a perfect score of 12. Seven students were close behind with a 10 or an 11 . Three students, all of whom wrote under four sentences, received the lowest possible score of 3 . The rest of the students fell into the average range.

The following student, who scored a 3, indeed wrote a story, but its contents were shallow and minimal. The writing included these few lines: "Once a pana time their a trak on the dark ochin. and then somone road it. and thay never saw him agin." The student who received a 
12 included all of the conventions listed on the rubric and used them in the creation of an imaginative, full, story based on the picture prompt:

One day long ago 4 men set off into the Deep Dark Sea. They began in the sea Late at Night. Just for fishing. But sudenly, they herd a Noise. And in a flash they hit land. A castle was perched upon the island. The four people got out and slowly walked up the gloomy hill. Inside the castle a little girl sat and wept. She looked back And stoped weeping. One of them walked up to the Child. What's wrong? my mother is sick! were is she? (story continues)

Overall, without explicit instruction, students were found to have the strongest skills in the inclusion of elements of a story and the weakest skills in sensory imagery, as noted by the means of 2.956 and 2.4 , respectively.

\section{Intervention: Week 1}

During the first week of intervention students engaged in sensory imagery writing after reading The Story of Frog Belly Rat Bone. Although students worked intently on drawing and coloring the scenes they imagined from the book, their writing samples with sensory imagery were weak. This aligns with the data observed in the pre-assessment results. Some students thought that sensory imagery meant saying the words see, hear, taste, touch, and smell, rather than using sentences that describe the actual sights, sounds, tastes, feelings, and smells. This example is a representation of the work of the whole group:

in Texas winter is like being in Alaska since it almost got snow evry winter. You can feel the heavy snow falling on you. You can taste the water and Hot chocolate. Also hear the children haveing fun in the snow. You see presents under your tree on 12/25. And lots of snow. You smell the fires. 
Some students used the same sensory word multiple times rather than using a variety of sensory language. Other students copied only the sensory words used in the examples provided during the lesson. In essence, the explicit instruction failed to elicit transfer from hearing a story with sensory imagery to imaginative writing with sensory imagery, in spite of the drawings and word discussions that accompanied the drawings.

\section{Intervention: Week 2}

When the intern dressed up as a baker students' imaginations were ignited and increased engagement levels were observed. Students moved around the room instead of listening to a lecture at their desks and showed excitement and willingness to learn. They were able to explain why the story sounded better to the audience with the addition of the synonyms that they chose. However, during the second day of the lesson, students began to struggle. They were able to use a thesaurus, but were weak in creating a poem. In retrospect, the leaders of the project placed too many expectations on the students with this assignment. The students were unsure how to write a poem using the synonyms and antonyms due to unfamiliarity with the structure of poetry and rhyme. They understood the concept of good word choice, but showed limited imagination and creativity when confronted with creating the writing.

The following student wrote the first two lines correctly. The third line was supposed to rhyme with the last word in the second sentence, and this student's does. However, the students were also supposed to make the final line about the tired word, which in this example is walk. No student understood this concept when creating his or her poem.

\section{Walk}

Hike, stroll, and shuffle.

Some people like to shuffle and wear ruffles. 


\section{Intervention: Week 3}

The onomatopoeia lesson was highly valuable. Students diligently worked with interest on their own comics. Because the students had performed so well, the mentor teacher decided to turn the comics writing a class book. This helped to reinforce that their writing had purpose and an audience, and that good writing should be praised. From this week on, onomatopoeia was continuously observed in students' writing samples, without prompt, in languages arts as well as in other curricular areas. Due to their personal freedom and investment in this lesson students retained this writing convention. Although this part of the action research was challenging because students had to simultaneously perform language arts and science, it was also the most successful. Students retained this lesson the longest, because their imaginations were activated during instruction, and they had an opportunity to creatively apply the writing lesson to another curricular area that had not previously required them to use their imagination.

This was the most successful portion of this action research. : Although students were asked to study both language arts and science, they retained the information the longest because they activated their imaginations and applied the writing to another curricular area.

\section{Intervention - Week 4}

Students struggled when practicing all these skills and conventions all at once. They chose to be silly and make up a funny story rather than focus on the outline we had written. They dropped characters and created new ones at random. Many of the new characters in the students' stories came from television shows and video games with which they were already familiar. The story was outlined to be about a girl who gets lost in the jungle after her plane crash-lands. Students ended up discussing sharks, alien underwater worlds, and monsters bringing down airplanes. They only added the conventions when prompted. Students failed to verbally bring the 
story to an end. The intern tried multiple times to keep students on the outline, but to no avail. Although the students engaged in imaginative storytelling, the lesson did not teach them to practice creative writing skills in a written format.

The final week was a repeat of the pre-assessment week. Students were asked to view the original work of art and begin writing a story about the art piece. Unlike the pre-instructional writing time, students began writing immediately. They were not shocked, confused, or lost. Most the papers were turned in within a short amount of time. The same rubric used in the preintervention prompt was used to score the post-intervention writing. The pre-assessment was compared to the post-assessment to assess growth or decline in student use of creative writing conventions without prompt. A t-test was used to compare the means on each indicator in the assessment. Table 3 shows the combined pre-assessment and post-assessment scores.

Four of the students received the same score on the post-assessment as they did on the pre-assessment. Of these, three had fairly high scores on the first writing sample. The fourth student however, was the lone student who earned a 3, and he also retained the same score on the post-writing assessment. Eleven students showed elevated scores from one to four points. Of these, nine were in the middle-to-upper range of scores on the first writing sample. The remaining two scored 3; and one of these students showed a four point gain, primarily in the area of story elements, while the other gained one point, raising his score from 3 to 4 . Eight students' scores dropped between one and three points. The students in this category were all in the middle and upper ranges of scores on the first sample, with one scoring 12 on the pre-assessment and 11 on the post-assessment. These scores, along with the t-test that was conducted on the pre- and post- assessment writing scores, suggest that there was some movement, albeit not significant (df $(22), \mathrm{t}=.689, \mathrm{p}<.05)$. 
Some changes were observed each week in each student's use of the writing conventions due the explicit instruction. The student who received a three in the pre-assessment example received a seven in the post-assessment. This student used voice and word choice, wrote an entire paragraph, and included real characters. The following is an excerpt from his paper: “Come on! We have bin on this old track for 7 month's! Look the casil. that's what we've ben wating for. Now..."

The student who received a perfect score of twelve in the pre-assessment dropped to an eleven on the post-assessment. He ended his story abruptly and only used the writing conventions sparingly. The following is an excerpt from his paper: "they ate scrumtios food and had a wonderful view. But the people in the down wondered what happened so no one everer went on that sea again."

The scores of the other students either fluctuated slightly or did not change at all.

\section{Observations}

At the beginning of the action it was found that the students who received the highest scores on the pre-assessment were those who were most frequently found reading and writing in their free time during the school day. This personal interest in reading could have influenced their scores. They were highly familiar with how to use writing conventions well and enjoyed creating a work of their own based on the content that surrounded them in their everyday lives. When they completed the post-assessment many of their scores dropped, because the second time around some students had lost interest or were no longer challenged by the assignment.

The students who wanted to complete their work quickly, regardless of the type of instruction given, tended to maintain their scores from the pre-assessment to the post-assessment. 
Explicit instruction of creative writing inventions did, in fact, increase their use in student writing without prompt. Although slight changes were noted, the rubric scores revealed minor increases in the use of creative writing conventions. Some students had a more cohesive and detailed story the second time, yet had decreased in their use of conventions. Meanwhile, other students increased their use of conventions, albeit in a broken and random story. Overall, the change within the scores was minor, and the use of writing conventions did not differ significantly at the $\mathrm{p}<.05$ level.

\section{Factors}

It was hypothesized that explicit instruction, designed to elicit imaginative writing, would foster imaginative writing among third grade students. Based on the results of the analysis of the weekly writing samples, as well as the analysis of the pre- and post-writing samples, it was noted that student imaginative writing showed signs of change, albeit in isolation rather than combination. One factor that possibly contributed to the failure of students to use writing conventions in imaginative writing is time. Six weeks was too short of a time period to see real change in young students' writing. In addition, the amount of time, a combined twenty to forty minutes per week, rendered limited opportunities for students to explore and expand their use of the conventions.

A second possible contributing factor to this failure is the number of conventions presented in limited instruction time. Students appeared overwhelmed by the number of conventions expected in the final writing prompt. They received one to two days of explicit instruction and one to three days of writing practice. Many students clearly understood the concept in large group discussions but did not demonstrate understanding independently. In spite of this, another concept was introduced each week. Too many conventions and expectations were 
presented in too short a period of time. This resulted in limited gains in the use of combined writing conventions in a response to a prompt about a work of art.

A third factor that possibly influenced the results of the study is the limitations placed on instruction by the expectations of the Texas Essential Knowledge and Skills (TEKS). Although this instruction focused on the conventions of creative writing, the lessons were all based on the TEKS, which tended to limit the interventions and thus the research. The lessons were based on the TEKS because instruction had to follow the required state mandates. The results may have differed if the study were conducted with more imaginative freedom. This further demonstrates that educators are often restricted by the state requirements, limiting the introduction, and/or extension of skills that can lead to imaginative writing.

Students did, indeed, work harder on assignments in which they had ownership and that were of interest to them, such as the comic writing. Often, they included topics and characters that were personally important to them in their writing. Another factor that contributed to the high level of success in the comic book writing was the connection to content covered in science that provided a foundation for creating superheroes that used the scientific concepts of force and energy. This connectivity seemed to have a positive influence on the writing, energizing students to perform at higher levels.

At this particular school, funding and resources depend on state examination scores. Students are taught how to pass the test rather than how to apply the skills they learn in an imaginative way outside of the classroom. Students approached the creative writing assignments with the same mindset — the testing mindset. They wanted to know how much to write, and what should be included. They feared that they would do something wrong in their writing and would 
therefore be punished with a bad grade. In addition, when students saw that their work would not be on their report card, they lost the desire to work hard.

\section{Conclusion}

This study examined whether or not explicit instruction of creative writing skills, presented in a lesson that activates student imagination, would increase imaginative, creative, and unprompted writing among third-grade students. The results show that the limited time devoted to explicit instruction had some effect on the students' writing when not prompted. I recommend actions, based on the results of this study, which would change methods.

First, this study was presented in too short a span of time. It would have been prudent to provide more time for students to study and practice each convention, ensuring competence and creativity, prior to continuing on to another convention. A few days each week was not sufficient time to see change in student writing.

The highest levels of student engagement, willingness, and creativity were observed during the week of onomatopoeia. Therefore, this would be a good starting point for further research. The writing convention being taught was connected to a science unit and gave students more freedom with a form of text that they enjoyed reading outside of school. Because their writing was rewarded with the creation of a class comic book, students felt proud of their work and were able to share it with their peers. This reward for their good writing solidified the content in their minds. When teachers review the standards that they are required to teach, they should seek opportunities in which to use creative writing across the curriculum. They should reward good writing with something other than a good score, and they should incorporate mentor texts and writings that interest motivate the students. These recommendations will lead to further action research in the writing classroom. 
Finally, students should have received a new picture or piece of art for the postassessment, rather than repeating their work on the same photo. This way, students would have fresh ideas. This would possibly bring about a greater use of the conventions. As researchers have not significantly studied the use of art as a prompt for writing, we have limited understanding of the benefits of using art in this context. Recommendations for further study would require testing this theory of alternate art pieces as prompts, in comparison to the use of same art pieces as post-writing assessments.

The testing culture of the American public school system has seeped into the minds of students. Somewhere between kindergarten and third grade students lose their confidence and imaginations in regards to academic writing. They want to follow rules in order to receive a good grade. They are unable to create and seem to resort to using other characters from television, video games, etc. Students have no desire to better themselves as writers, because they only want to do as they are instructed, so they can move on to another activity.

If teachers want to increase their students' use of imagination then it is incumbent upon them to begin with creative writing. It may seem like a small place to start, but creative writing has an imaginative power. Getting in the routine of imagination activation will have an effect on student creative writing (Barber, 2003, p. 8). We must practice daily and not let the creativity fall in importance relative to tests. Baroness Mary Warnock states, "In education, we have a duty to educate the imagination above all else," (Clark, 1997, p.19). The loss of imagination in children will be more detrimental to our country than failing scores on examinations. Imagination is what pushes us into tomorrow. Teaching creative writing skills and encouraging imagination is imperative because "it is early practice for students to see the world around them in living detail and [capture] its energy in lines on a page," (Schneider, 2006, p. 20). Being an imaginative 
writer frees the child, provides another form of personal expression, and shows him multiple perspectives from which to view his world. Unfortunately, today the problem remains. We cannot afford to share the attitude of the following educator, who states: "This is not what I am being paid to do. I'm being paid to equip these children with literacy skills, rather than helping them to make sense of their lives and grow up [through creative writing], "' Dart, 2001, p.68). Pablo Picasso said it best when he stated, "All children are artists. The problem is how to remain an artist once you grow up." There is no perfect way to do this, but we must continue to practice the best ways. Imagination is too important to lose. 


\section{References}

Allsburg, Chris V. (1984). Another time, Another place. Retrieved March 24, 2013 from http://graphics8.nytimes.com/images/2011/11/13/books/review/Marcus2/Marcus2popup.jpg

Barber, Susan. (2003, July). Imagination in writing and teaching. Speech presented at the IERG conference at Simon Fraser University, Vancouver, BC. Retrieved from

http://www.ierg.net/confs/2003/proceeds/Barber.pdf

Clark, Janice E. (1997). Of writing, imagination and dialogue: A transformative experience. New Directions for Adult and Continuing Education, 74, 13-22. doi: 10.1002/ace.7402

Cook, Luella, B. (1931). Creative writing in the classroom: It's how, when, what, and what not. The English Journal, 20, 195-202. Retrieved from http://www.jstor.org/stable/803652

Dart, Lisa. (2001). Literacy and the lost world of the imagination. Educational Research, 43, 6377. Retrieved from http://www.tandfonline.com/doi/abs/10.1080/00131880010021285\#preview

Ering, Timothy B. (2008). The story of frog belly rat bone. Candlewick Press.

Littwin, Maxwell. (1935). Three methods of developing imagination in pupils' writing. The English Journal, 24, 654 - 661. Retrieved from http://www.jstor.org/stable/804784

Mills, Beth. (1983). Imagination: The connection between writing and play. Educational Leadership, 50-53. Retrieved from http://www.ascd.org/ASCD/pdf/journals/ed_lead/el_198303_mills.pdf

Pavlik, Lisa (2011). Structured imagination and the writing of creative stories. The Journal of Creative Behavior, 36, 117-137. doi: 10.1002/j.2162-6057.2002.tb01060.x

Schneider, Dean. (2006, May). Teaching poetry, jump-starting imaginations. Book Links, 15, 20 21.

Tompkins, Gail E. (2012). Chapter 6: Descriptive writing. Ramos Aurora. (6 ${ }^{\text {th }}$ Edition), Teaching Writing: Balancing Process and Product (134-153). Boston, MA: Pearson. 
Structuring the Imagination 25

Table 1. Pre-Assessment Rubric

\begin{tabular}{|c|c|c|c|c|c|}
\hline & $\mathbf{1}$ & $\mathbf{2}$ & $\mathbf{3}$ & $\mathbf{4}$ & Comments \\
\hline $\begin{array}{c}\text { Not Present } \\
\text { Elements of a Story } \\
\begin{array}{c}\text { Characters, Setting, } \\
\text { Beginning, Middle, End } \\
\text { Present }\end{array}\end{array}$ & $\begin{array}{c}\text { Mostly } \\
\text { Present }\end{array}$ & $\begin{array}{c}\text { Fully } \\
\text { Present }\end{array}$ & \\
\hline $\begin{array}{c}\text { Strong Word Choice } \\
\text { Synonyms, Antonyms, } \\
\text { Onomatopoeia, Dialogue }\end{array}$ & & & & & \\
\hline $\begin{array}{c}\text { Sensory Language } \\
\text { Writing appeals to the five } \\
\text { senses }\end{array}$ & & & & & \\
\hline
\end{tabular}


Structuring the Imagination 26

Table 2. Pre-Assessment Results

\begin{tabular}{|c|c|c|c|c|}
\hline Student & Elements of a Story & Word Choice & Sensory Imagery & TOTAL \\
\hline 1 & 3 & 4 & 3 & 10 \\
\hline 2 & 1 & 1 & 1 & 3 \\
\hline 3 & 3 & 2 & 2 & 7 \\
\hline 4 & 3 & 3 & 3 & 9 \\
\hline 5 & 4 & 4 & 2 & 10 \\
\hline 6 & 3 & 2 & 2 & 7 \\
\hline 7 & 3 & 2 & 2 & 7 \\
\hline 8 & 4 & 4 & 3 & 11 \\
\hline 9 & 4 & 4 & 4 & 12 \\
\hline 10 & 3 & 2 & 2 & 7 \\
\hline 11 & 4 & 4 & 3 & 11 \\
\hline 12 & 2 & 3 & 3 & 8 \\
\hline 13 & 4 & 2 & 2 & 8 \\
\hline 14 & 1 & 1 & 1 & 3 \\
\hline 15 & 4 & 3 & 3 & 10 \\
\hline 16 & 3 & 2 & 2 & 7 \\
\hline 17 & 3 & 2 & 3 & 8 \\
\hline 18 & 1 & 1 & 1 & 3 \\
\hline 19 & 3 & 1 & 2 & 6 \\
\hline 20 & 3 & 3 & 3 & 9 \\
\hline 21 & 3 & 4 & 4 & 11 \\
\hline 22 & 2 & 3 & 2 & 7 \\
\hline 23 & 4 & 3 & 3 & 10 \\
\hline Mean & 2.956521739 & 2.608695652 & 2.434782609 & 8 \\
\hline
\end{tabular}


Structuring the Imagination 27

Table 3. Combined Pre-Assessment and Post-Assessment Scores

\begin{tabular}{|c|c|c|c|c|c|c|c|c|c|}
\hline $\begin{array}{c}\text { Stud } \\
\text { ent }\end{array}$ & $\begin{array}{c}\text { Elements of } \\
\text { a Story }\end{array}$ & $\begin{array}{c}\text { Elements of } \\
\text { a Story } \\
\text { POST }\end{array}$ & $\begin{array}{c}\text { Word } \\
\text { Choice }\end{array}$ & $\begin{array}{c}\text { Word } \\
\text { Choice } \\
\text { POST }\end{array}$ & $\begin{array}{l}\text { Sensory } \\
\text { Imagery }\end{array}$ & $\begin{array}{c}\text { Sensory } \\
\text { Imagery } \\
\text { POST }\end{array}$ & TOTAL & $\begin{array}{c}\text { POST } \\
\text { TOTAL }\end{array}$ & FINDINGS \\
\hline 1 & 3 & 3 & 4 & 4 & 3 & 3 & 10 & 10 & 0 \\
\hline 2 & 1 & 3 & 1 & 2 & 1 & 2 & 3 & 7 & 4 \\
\hline 3 & 3 & 2 & 2 & 2 & 2 & 2 & 7 & 6 & -1 \\
\hline 4 & 3 & 3 & 3 & 3 & 3 & 3 & 9 & 9 & 0 \\
\hline 5 & 4 & 3 & 4 & 3 & 2 & 2 & 10 & 7 & -3 \\
\hline 6 & 3 & 3 & 2 & 3 & 2 & 3 & 7 & 9 & 2 \\
\hline 7 & 3 & 3 & 2 & 4 & 2 & 2 & 7 & 9 & 2 \\
\hline 8 & 4 & 3 & 4 & 3 & 3 & 2 & 11 & 8 & -3 \\
\hline 9 & 4 & 3 & 4 & 4 & 4 & 4 & 12 & 11 & -1 \\
\hline 10 & 3 & 3 & 2 & 3 & 2 & 3 & 7 & 9 & 2 \\
\hline 11 & 4 & 4 & 4 & 4 & 3 & 2 & 11 & 10 & -1 \\
\hline 12 & 2 & 4 & 3 & 3 & 3 & 2 & 8 & 9 & 1 \\
\hline 13 & 4 & 3 & 2 & 3 & 2 & 2 & 8 & 8 & 0 \\
\hline 14 & 1 & 2 & 1 & 1 & 1 & 1 & 3 & 4 & 1 \\
\hline 15 & 4 & 3 & 3 & 2 & 3 & 2 & 10 & 7 & -3 \\
\hline 16 & 3 & 4 & 2 & 3 & 2 & 2 & 7 & 9 & 2 \\
\hline 17 & 3 & 4 & 2 & 4 & 3 & 2 & 8 & 10 & 2 \\
\hline 18 & 1 & 1 & 1 & 1 & 1 & 1 & 3 & 3 & 0 \\
\hline 19 & 3 & 3 & 1 & 2 & 2 & 2 & 6 & 7 & 1 \\
\hline 20 & 3 & 4 & 3 & 2 & 3 & 2 & 9 & 8 & -1 \\
\hline 21 & 3 & 3 & 4 & 2 & 4 & 2 & 11 & 7 & -2 \\
\hline 22 & 2 & 3 & 3 & 3 & 2 & 3 & 7 & 9 & 2 \\
\hline 23 & 4 & 4 & 3 & 4 & 3 & 4 & 10 & 12 & 2 \\
\hline
\end{tabular}


Structuring the Imagination 28

\begin{tabular}{|c|c|c|c|c|c|c|c|c|c|}
\hline ME & 2.956521739 & 3.086956522 & 2.608695652 & 2.826086957 & 2.434782609 & 2.304347826 & 8 & 8.17 & \\
AN & & & & & & & & \\
\hline
\end{tabular}

